\title{
Satellite data potential for landslide studies in tropical regions.
}

\begin{abstract}
Purpose - The purpose of this paper is to show that satellite data applicability for landslides studies is given concentration in tropical regions, which have two limitations; regular cloud cover and thick vegetation. Design/methodology/approach - Landslide studies have three categories: mapping, zonation, and monitoring. High spatial resolution images are convenient for mapping. Since the slope and slope materials are the dominant parameters for slide potential, a high resolution DEM produced from the above data with classification of multispectral data will be vital for zonation. Weather-free and penetration are advantages that make radar images essential for monitoring. Findings - A composition of satellite data with support of aerial photography, with its high spatial resolution, will give an excellent spatial database for these studies. Originality/value - Satellite remote sensing data are applicable for landslides studies in non-accessible mountainous tropical regions.
\end{abstract}

Keyword: Landslides; Natural disasters; Visual databases. 